\title{
MOLECULAR MECHANISMS OF CARDIAC CELL DAMAGE AFTER ASPHYXIA AND HEMORRHAGE
}

\author{
M. Kalbitz', S. Schwarz², I. Lackner¹, B. Weber', F. Gebhard', \\ H. Hummler ${ }^{2}$, M. R. Mendler ${ }^{2}$
}

1 Department of Trauma, Hand, Plastic and Recontstructive Surgery, University of Ulm, Ulm, Germany 2 Division of Neonatology and Pediatric Critical Care, Department of Pediatrics and Adolescent Medicine, University of Ulm, Ulm, Germany

Background: Cardiac cell damage is associated with systemic increase of troponin I (Tnl) concentration and increased mortality after trauma. In newborns with asphyxia troponin increase is likewise associated with increased mortality. In neonates perinatal blood loss in combination with intrauterine hypoxia (asphyxia) and hypovolemia is a potentially life-threatening condition. The purpose of this study was to describe the morphological, immunological and structural alterations in cardiac tissue after asphyxia with hemorrhage in neonatal pigs.

Methods: Neonatal pigs underwent asphyxia, followed by resuscitation either with blood or crystalloid transfusion. 4 hours after ROSC (return of spontaneous circulation) heart tissue and blood samples were collected. Analysis of serum heart fatty acid binding protein (H-FABP) and cardiac specific Tnl levels as well as the activation of the complement system and the appearance of damage associated molecular patterns (DAMPs) were executed. Local alterations in the cardiac left ventricle after asphyxia and hemorrhage were assessed by histology and immunohistor

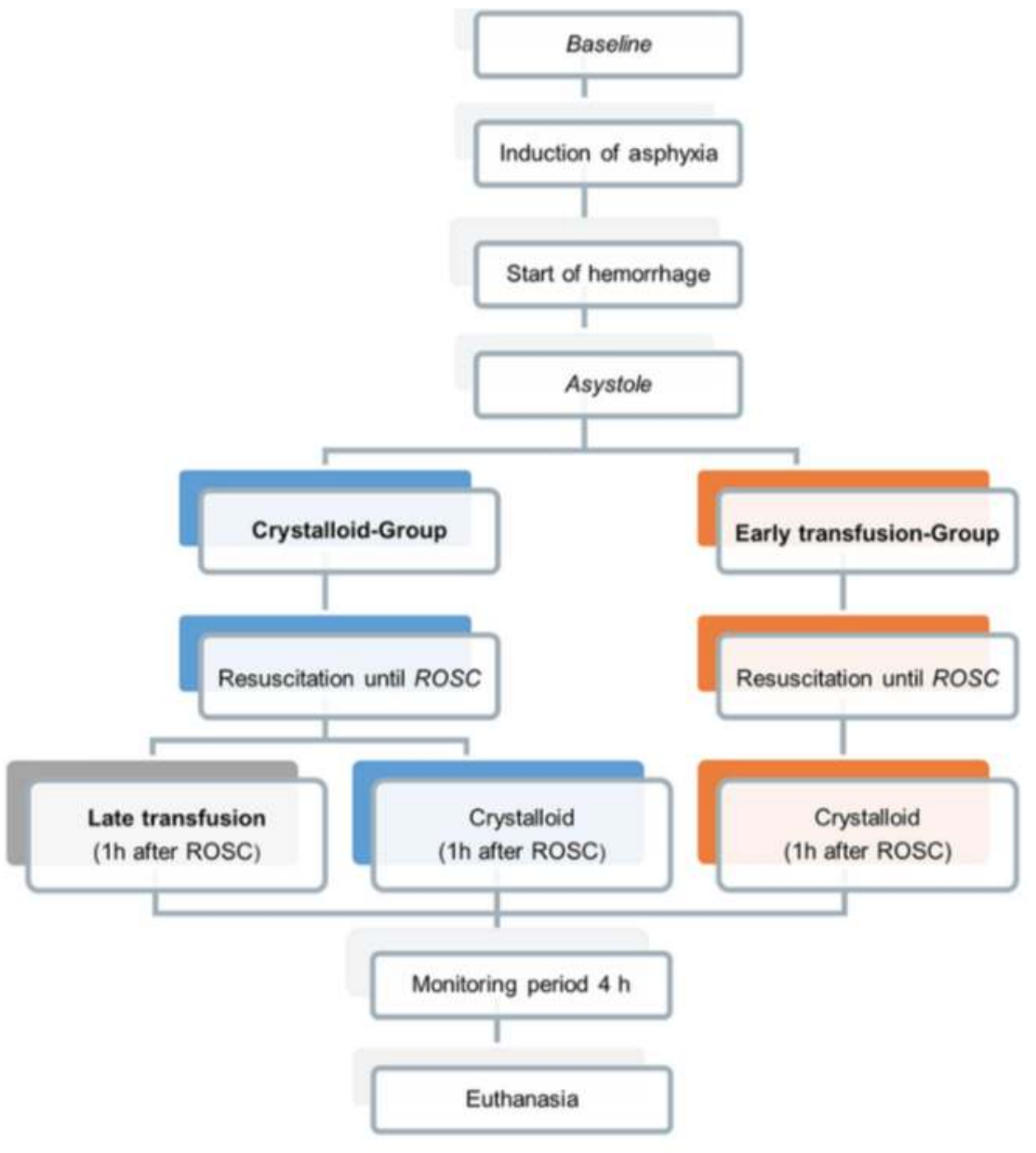

Arterial Oxygen Saturation

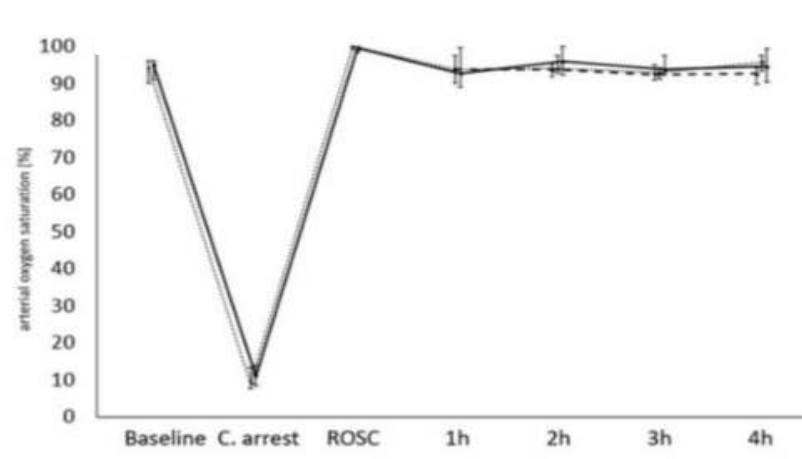

Base Excess
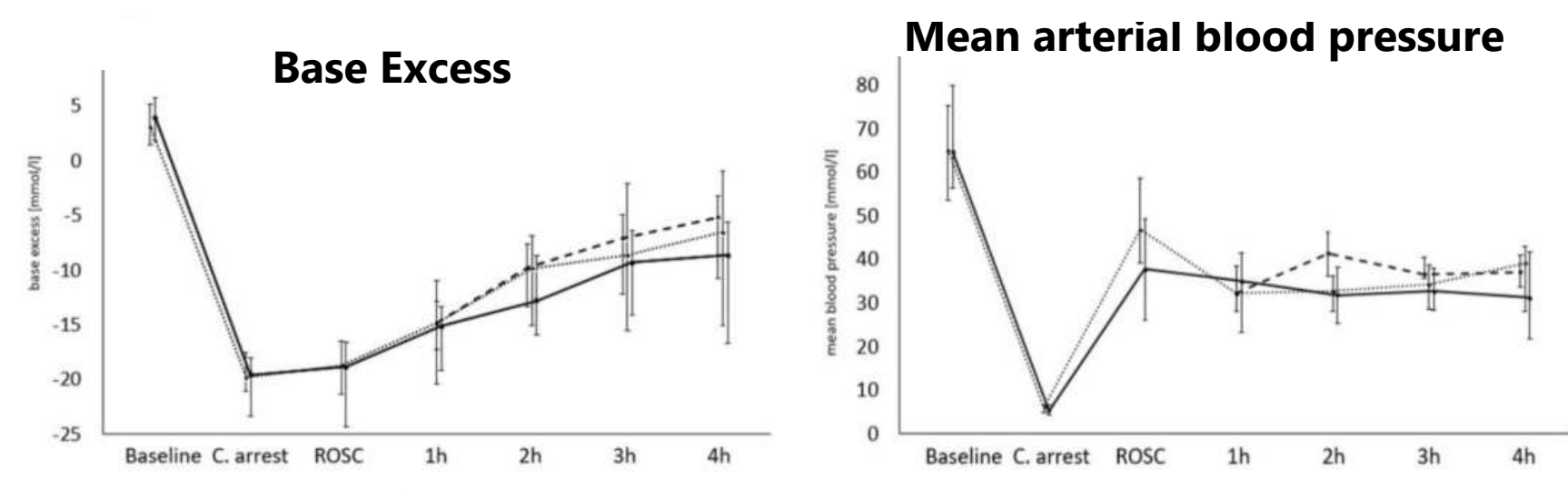

Results:
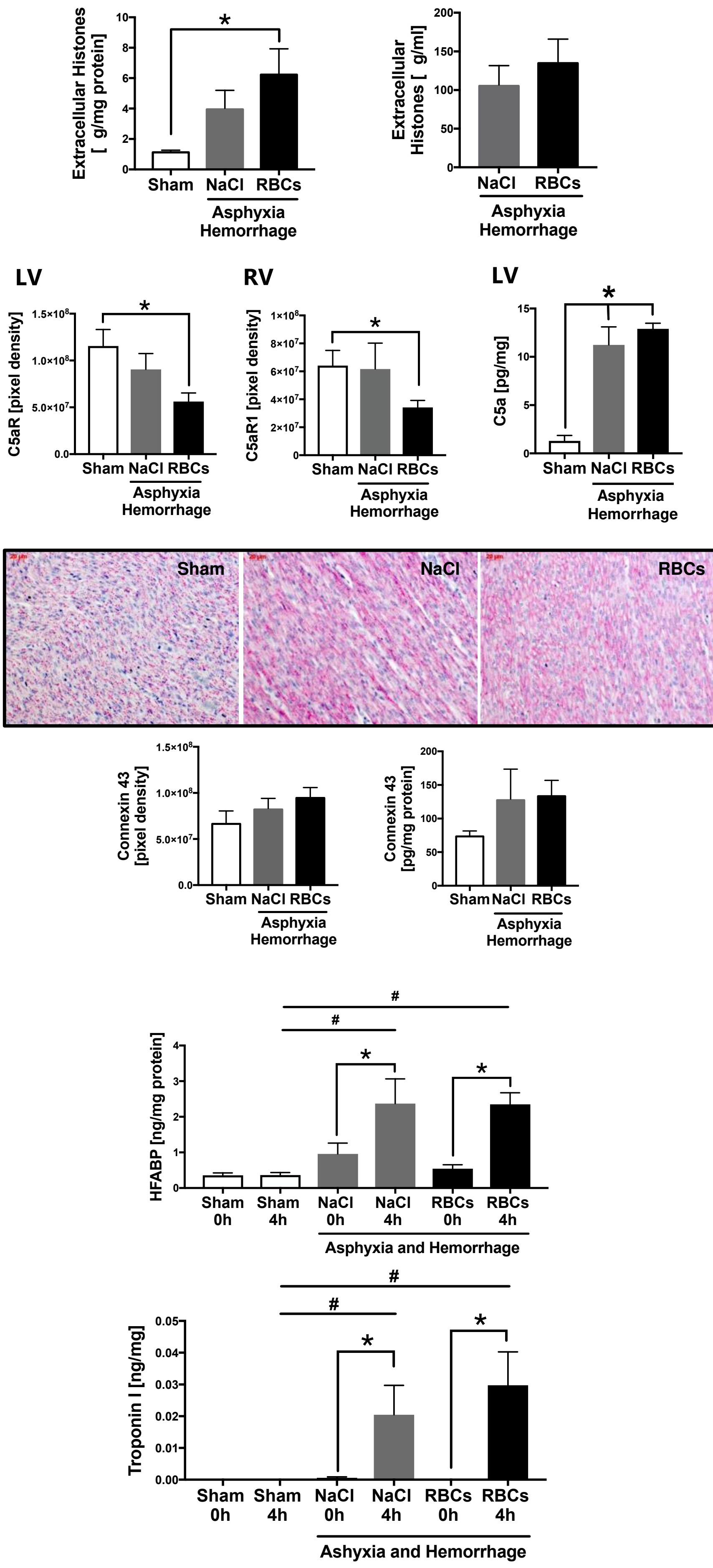

Conclusions: Asphyxia and hemorrhage leads to a remarkable damage of the heart including alteration of gap junction protein $\mathrm{Cx} 43$. 